\title{
Evaluation of Hybrid Vesicles in an Intestinal Cell Model Based on Structured Paper Chips
}

Paula De Dios Andres, Isabella N. Westensee, Edit Brodszkij, Miguel A. Ramos-Docampo, Noga Gal, Brigitte Städler*

Interdisciplinary Nanoscience Center (iNANO), Aarhus University, Gustav Wieds Vej 14, 8000 Aarhus, Denmark

*bstadler@inano.au.dk

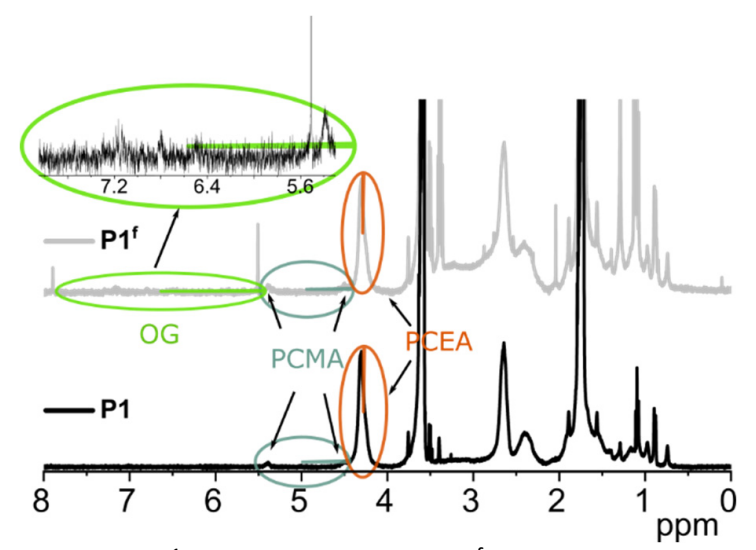

Figure S1. ${ }^{1} \mathrm{H}$ NMR spectra of $\mathrm{P} 1{ }^{\mathrm{f}}$ in THF-d8 and P1 in THF-d4. The Mw_PCMA $=5200 \mathrm{Da}$, and Mw_PCEA $=25 \mathrm{kDa}$ and $24 \mathrm{kDa}$ in $\mathrm{P} 1$ and P1f, respectively, based on NMR.

Table S1. Hydrodynamic diameter $\left(D_{h}\right)$ and polydispersity index (PDI) of the different HVs and liposomes as obtained by DLS.

\begin{tabular}{|c|c|c|}
\hline & $\mathbf{D}_{\mathbf{h}}(\mathbf{n m})$ & PDI \\
\hline $\mathrm{HV}_{0.4}$ & $164 \pm 4$ & $0.06 \pm 0.02$ \\
\hline $\mathrm{HV}_{0.4}^{\mathrm{Mix}}$ & $178 \pm 9$ & $0.09 \pm 0.02$ \\
\hline $\mathrm{HV}_{0.4}^{\mathrm{Rho}}$ & $164 \pm 8$ & $0.06 \pm 0.02$ \\
\hline $\mathrm{HV}_{0.4}^{\mathrm{OG}}$ & $155 \pm 6$ & 0.24 \\
\hline $\mathrm{HV}_{0.1}^{\mathrm{Mix}}$ & 201 & 0.08 \\
\hline $\mathrm{HV}_{0.1}^{\mathrm{Rho}}$ & 139 & 0.07 \\
\hline $\mathrm{HV}_{0.1}^{\mathrm{OG}}$ & 155 & $0.07 \pm 0.03$ \\
\hline $\mathrm{HV}_{0.8}^{\mathrm{Mix}}$ & $198 \pm 0.9$ & 0.14 \\
\hline $\mathrm{HV}_{0.8}$ & 225 & 0.10 \\
\hline $\mathrm{L}_{9}$ & 150 & 0.10 \\
\hline $\mathrm{L}_{25}$ & 151 & 0.13 \\
\hline $\mathrm{L}_{\mathrm{PCMA}-0.4}$ & 145 & 0.11 \\
\hline $\mathrm{L}_{\mathrm{PCMA}-0.8}$ & 138 & \\
\hline
\end{tabular}


a) $\mathrm{HV}_{0.1}$

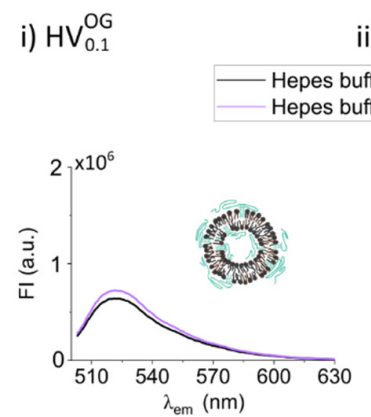

ii) $H V_{0.1}^{\text {Rho }}$

$$
\text { TX }+1 \%
$$

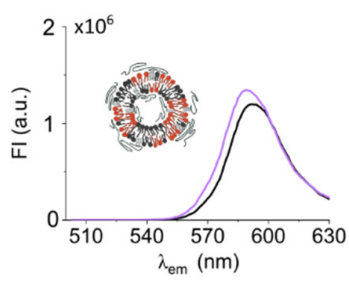

b) $\mathrm{HV}_{0.4}$

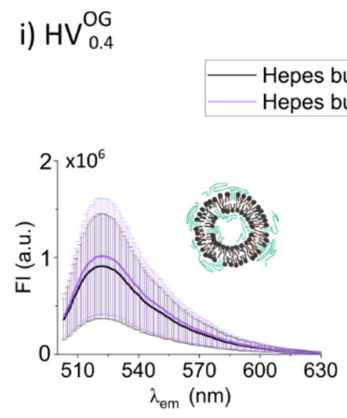

ii) $\mathrm{HV}_{0.4}^{\text {Rho }}$

epes buffer

$+1 \% \mathrm{TX}$

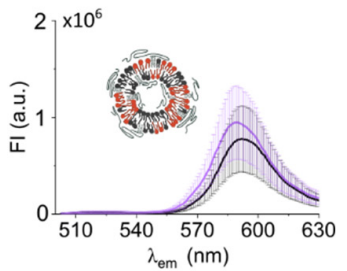

Figure S2. Fluorescence emission spectra of the different HVs: a) i) Fluorescent emission spectra $\left(\lambda_{\mathrm{ex}} / \lambda_{\mathrm{em}}=488 / 503-650 \mathrm{~nm}\right.$ ) of $\mathrm{HV}_{0.1}^{\mathrm{OG}}$ before (black line) and after treatment with $1 \% \mathrm{TX}$ (purple line). ii) Fluorescent emission spectra $\left(\lambda_{\text {ex }} / \lambda_{\text {em }}=488 / 503-650 \mathrm{~nm}\right.$ ) of $\mathrm{HV}_{0.1}^{\text {Rho }}$ before (black line) and after treatment with $1 \%$ TX (purple line) $(n=1)$. b) i) Fluorescent emission spectra $\left(\lambda_{\mathrm{ex}} / \lambda_{\mathrm{em}}=488 / 503-650\right.$ $\mathrm{nm}$ ) of $\mathrm{HV}_{0.4}^{\mathrm{OG}}$ before (black line) and after treatment with $1 \% \mathrm{TX}$ (purple line). ii) Fluorescent emission spectra $\left(\lambda_{\mathrm{ex}} / \lambda_{\mathrm{em}}=488 / 503-650 \mathrm{~nm}\right.$ ) of $\mathrm{HV}_{0.4}^{\mathrm{Rho}}$ before (black line) and after treatment with $1 \% \mathrm{TX}$ (purple line) $(n=3)$.
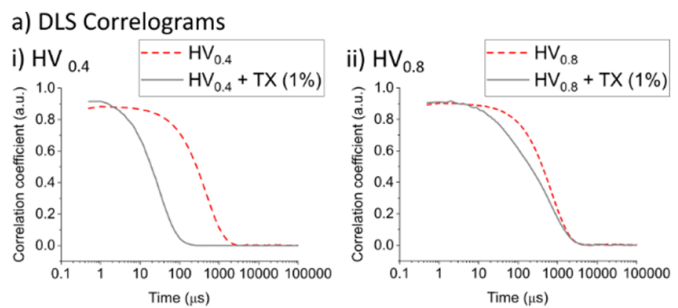

b) GHV

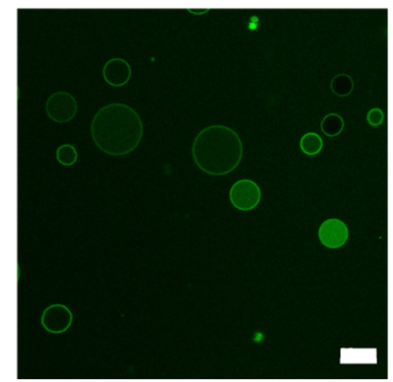

Figure S3. Correlograms of $\mathrm{HV}_{0.4}$ (i) and $\mathrm{HV}_{0.8}$ (ii) before and after $\mathrm{TX}$ (1\% final concentration) addition. b) CLSM image of GHVs (green: $P 1^{f}$ ). The high background signal as well as the high fluorescent signal inside the GHVs most likely originates from (polymeric) micelles. The scale bar is $10 \mu \mathrm{m}$.

Table S2. Hydrodynamic diameter $\left(D_{h}\right)$ and polydispersity index (PDI) of $\mathrm{HV}_{0.4}$ before and after TX (1\% final concentration) addition.

\begin{tabular}{|c|c|c|}
\hline & $\mathbf{D}_{\mathbf{h}}(\mathbf{n m})$ & PDI \\
\hline $\mathrm{HV}_{0.4}$ & $164 \pm 4$ & $0.06 \pm 0.02$ \\
\hline $\mathrm{HV}_{0.4}+\mathrm{TX}(1 \%)$ & 10 & 0.14 \\
\hline $\mathrm{HV}_{0.8}$ & $221 \pm 16$ & 0.09 \\
\hline $\mathrm{HV}_{0.8}+\mathrm{TX}(1 \%)$ & $71 \pm 1$ & 0.79 \\
\hline
\end{tabular}


a) $\mathrm{L}$

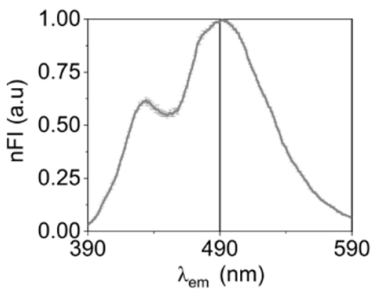

b) Vesicles with cholestero

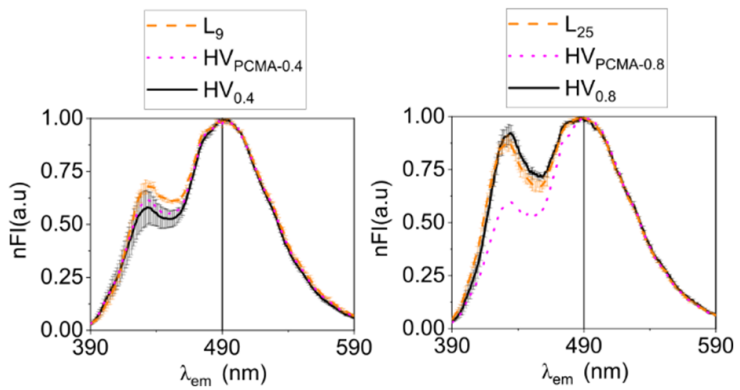

Figure S4. Membrane Fluidity Assay using Laurdan. a) Emission spectra of L (0\% Chol) after 45 min incubation with Laurdan. b) Comparison of emission spectra of $\mathrm{HV}_{0.4}, \mathrm{~L}_{9}$ and $\mathrm{HV}_{\mathrm{PCMA}-0.4}$ (left) and of $\mathrm{HV}_{0.8}, \mathrm{~L}_{25}$ and $\mathrm{HV}_{\mathrm{PCMA}-0.8}$ (right). Samples in the respective graphs contain the same amount of cholesterol. The individual repeats are normalized to the emission at $\lambda_{\mathrm{em}}=490 \mathrm{~nm}$ to account for the fluorophore concentration differences $(n=2)$.

a) Stability in HEPES

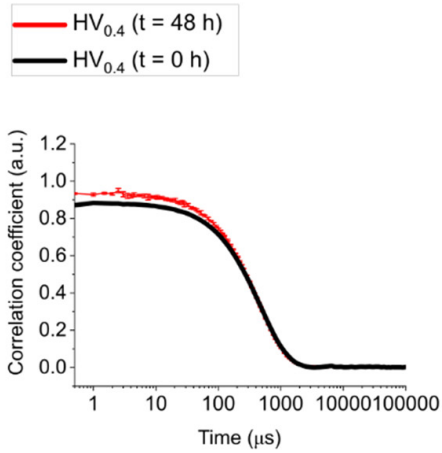

b) HEPES buffer + FBS

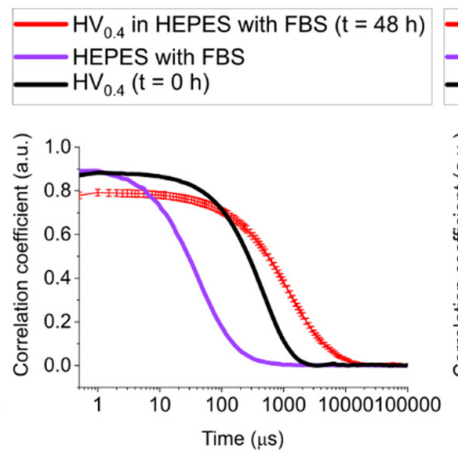

c) Cell media

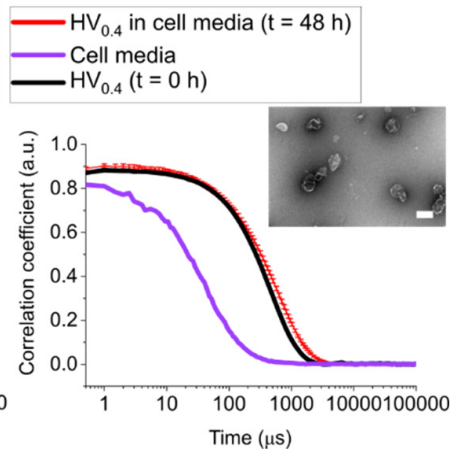

Figure S5. $\mathrm{HV}_{0.4}$ in different environments. a) Correlogram of $\mathrm{HV}_{0.4}$ at $\mathrm{t}=\mathrm{O} \mathrm{h}$ (black line) and after $48 \mathrm{~h}$ (red line) at $37{ }^{\circ} \mathrm{C}$ on a shaker $\left(250 \mathrm{rpm}\right.$ ) in HEPES buffer. $\mathrm{HV}_{0.4}$ in HEPES buffer with $10 \% \mathrm{FBS}(\mathrm{b})$ or in cell media (MEM phenol red free plus all the supplements), c) after $24 \mathrm{~h}$ at $37{ }^{\circ} \mathrm{C}$ and $250 \mathrm{rpm}$. The correlograms of HEPES buffer containing $10 \%$ FBS (purple line in b) or cell media (purple line in c) are shown for comparison ( $\mathrm{n}=2$ ). TEM image of $\mathrm{HV}_{0.4}$ in media after $48 \mathrm{~h}$ incubation (Scale bar: $200 \mathrm{~nm}$ ).

Table S3. Hydrodynamic diameter $\left(D_{h}\right)$ and polydispersity index (PDI) of $H V_{0.4}$ when incubated in different solutions or after crossing the paper chips.

\begin{tabular}{|c|c|c|}
\hline Sample & $\mathbf{D}_{\mathbf{h}}(\mathbf{n m})$ & PDI \\
\hline $\mathrm{HV}_{0.4}$ in HEPES buffer $(0 \mathrm{~h})$ & $164 \pm 4$ & $0.06 \pm 0.02$ \\
\hline $\mathrm{HV}_{0.4}$ in HEPES buffer $\left(37^{\circ} \mathrm{C}, 48 \mathrm{~h}\right)$ & $151 \pm 1$ & $0.08 \pm 0.02$ \\
\hline $\mathrm{HV}_{0.4}$ in HEPES buffer $+\mathrm{FBS}\left(37^{\circ} \mathrm{C}, 24 \mathrm{~h}\right)$ & $137 \pm 8$ & $0.5 \pm 0.1$ \\
\hline $\mathrm{HV}_{0.4}$ in HEPES buffer $+\mathrm{FBS}\left(37^{\circ} \mathrm{C}, 48 \mathrm{~h}\right)$ & $403 \pm 11$ & $0.6 \pm 0.0$ \\
\hline $\mathrm{HV}_{0.4}$ in cell media $\left(37^{\circ} \mathrm{C}, 24 \mathrm{~h}\right)$ & $139 \pm 2$ & $0.2 \pm 0.0$ \\
\hline
\end{tabular}




\begin{tabular}{|c|c|c|}
\hline $\mathrm{HV}_{0.4}$ in cell media $\left(37^{\circ} \mathrm{C}, 48 \mathrm{~h}\right)$ & $184 \pm 3$ & $0.3 \pm 0.0$ \\
\hline $\mathrm{HV}_{0.4}$ after crossing a uncoated paper chip & $153 \pm 11$ & $0.2 \pm 0.1$ \\
\hline $\mathrm{HV}_{0.4}$ after crossing a PLL coated paper chip & Not detectable & Not detectable \\
\hline $\mathrm{HV}_{0.4}$ after crossing a GelMA coated paper chip & $150 \pm 5$ & $0.2 \pm 0.1$ \\
\hline $\mathrm{HV}_{0.4}$ after crossing a peeled uncoated paper chip & $354 \pm 24$ & $0.6 \pm 0.0$ \\
\hline $\mathrm{HV}_{0.4}$ after crossing a peeled PLL coated paper chip & $670 \pm 43$ & $0.5 \pm 0.1$ \\
\hline $\mathrm{HV}_{0.4}$ after crossing a peeled GelMA coated paper chip & $142 \pm 5$ & $0.4 \pm 0.1$ \\
\hline
\end{tabular}

a) PLL $_{F}$
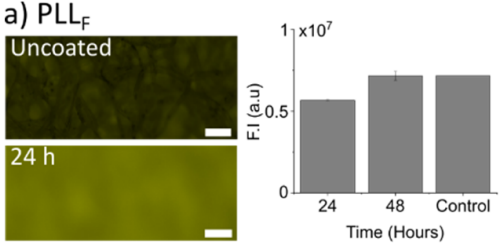

b) GeIMA

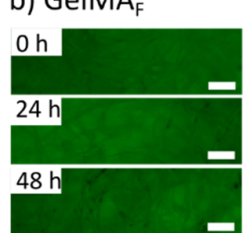

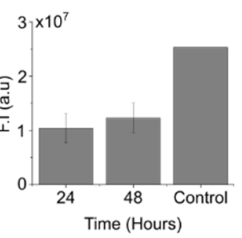

Figure S6. Paper chip coated with PLL or GelMA: a) Fluorescent microscopy image of the chip before (showing the autofluorescence of the paper) and after the coating with PLL (left). Fluorescence intensity measures of the liquid underneath the chip after 24 and $48 \mathrm{~h}$ incubation (right) b) Wide field microcopy image of the GelMA $A_{F}$ coated chip immediately after crosslinking $(0 \mathrm{~h})$, after $24 \mathrm{~h}$ and $48 \mathrm{~h}$ incubation (left). Fluorescence intensity measures of the liquid underneath the chip after $24 \mathrm{~h}$ and 48 $h$ incubation (right). All scale bars are $100 \mu \mathrm{m}$. The data are expressed as mean $\pm S D(n=3)$. 
a) Regular paper - $\mathrm{HV}_{0.4}$
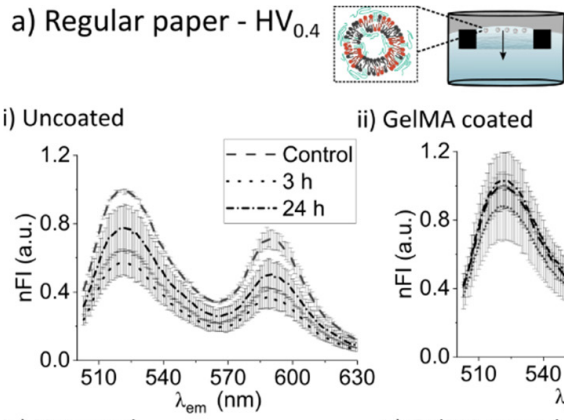

ii) GelMA coated
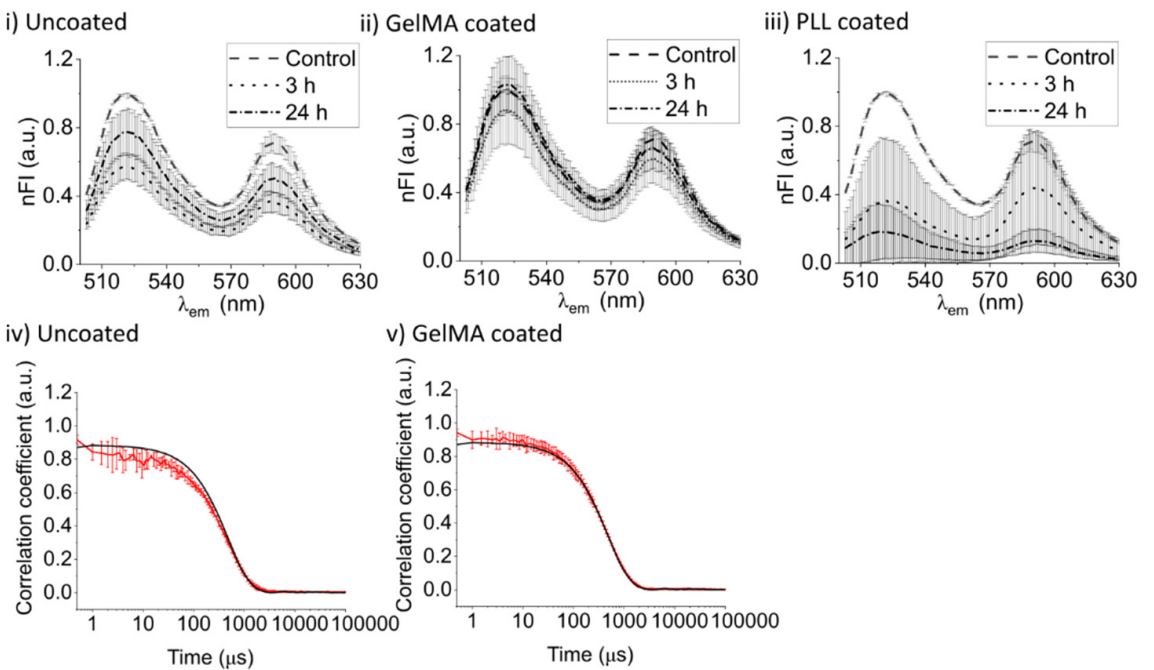

b) Peeled paper - $\mathrm{HV}_{0.4}$
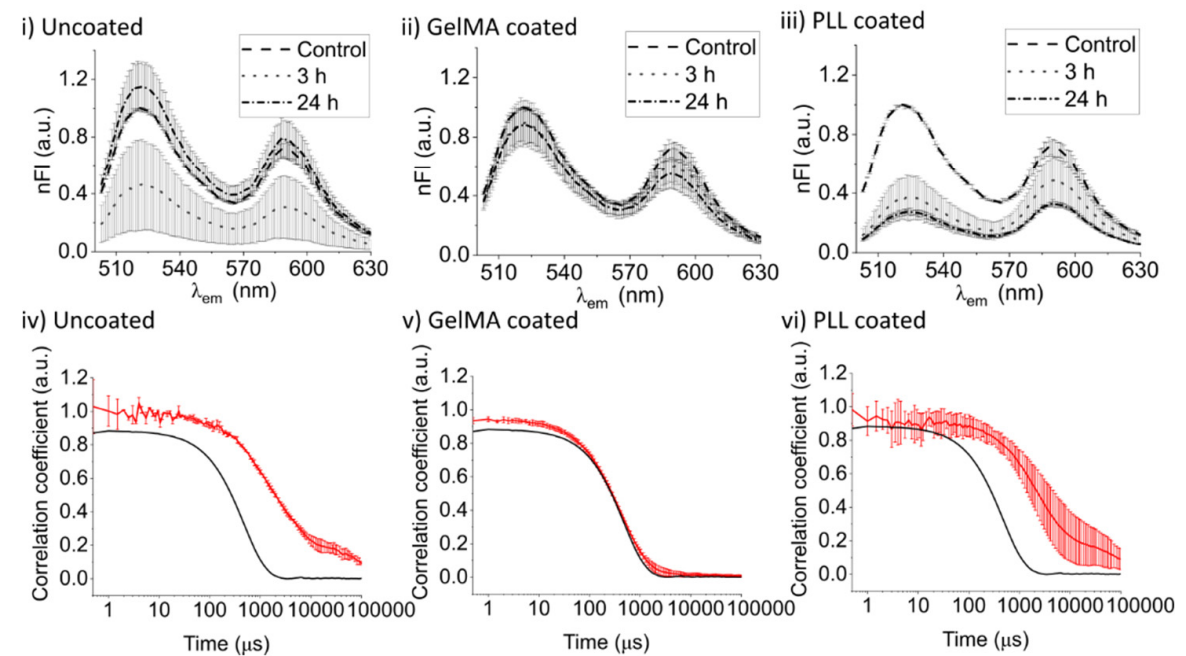

Figure S7. $\mathrm{HV}_{0.4}$ crossing regular (a) and peeled (b) paper chips. Fluorescence emission spectra (top) and correlograms obtained from DLS (bottom, black - controls in HEPES buffer, red - solution in the wells after crossing the different paper chip) of the solution in the wells with floating i/iv) uncoated paper chips, ii/v) GelMA coated paper chips and iii/vi) PLL coated paper chips $3 \mathrm{~h}$ and $24 \mathrm{~h}$ after $\mathrm{HV}_{0.4}^{\text {mix }}$ were added to the hydrophilic central part of the paper chips. $(n=2)$ 


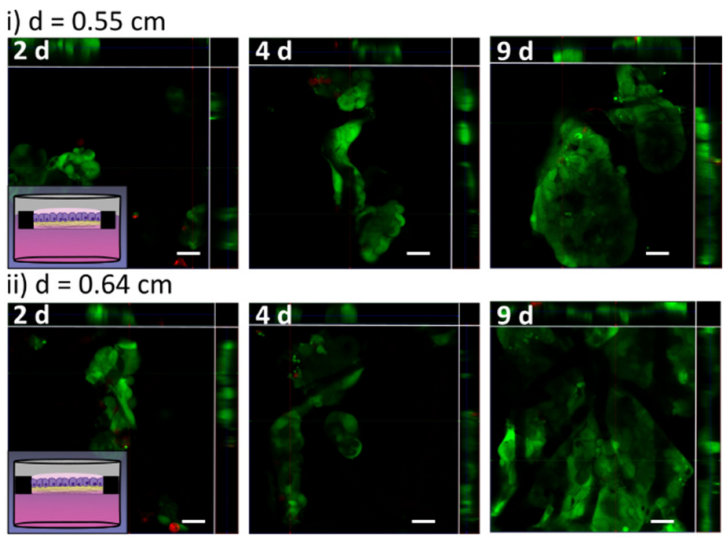

Figure S8. Paper Chip Size. Representative CLSM images of Caco-2 cells cultured in PLL coated paper chips with a diameter of $d=0.55 \mathrm{~cm}$ (i) and $d=0.64 \mathrm{~cm}$ (ii). The side-views of 3D images are shown on top and right of the CLSM images (green: calcein-AM, red: ethidium homodimer-1, cell seeding density: 17500 cells per chip). Scale bars $25 \mu \mathrm{m} .(n=3)$

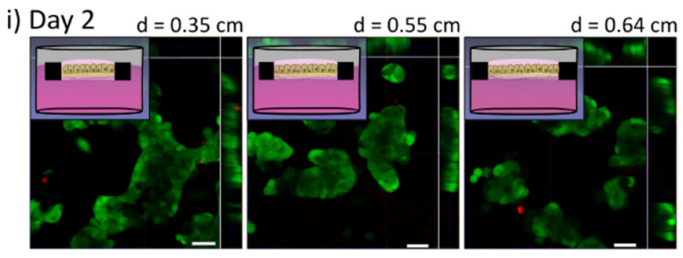

ii) Day 4

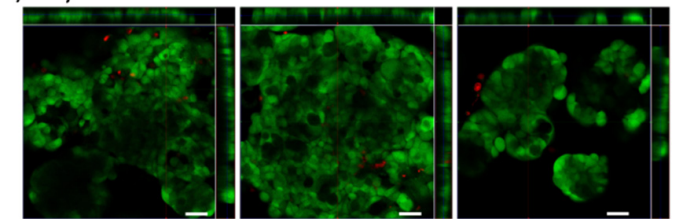

iii) Day 9

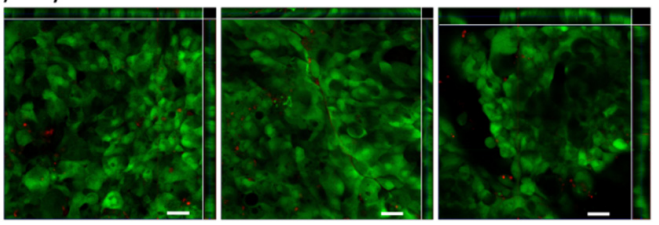

Figure S9. Representative CLSM images of HT29-MTX-E12 cells cultured in PLL coated paper chips of different diameters for $2 \mathrm{~d}$ (i), $4 \mathrm{~d}$ (ii) and $9 \mathrm{~d}$ (iii). The side-views of 3D images are shown on top and right of the CLSM images (green: calcein-AM, red: ethidium homodimer-1). Scale bars are $25 \mu \mathrm{m}$. $(n=3)$ 

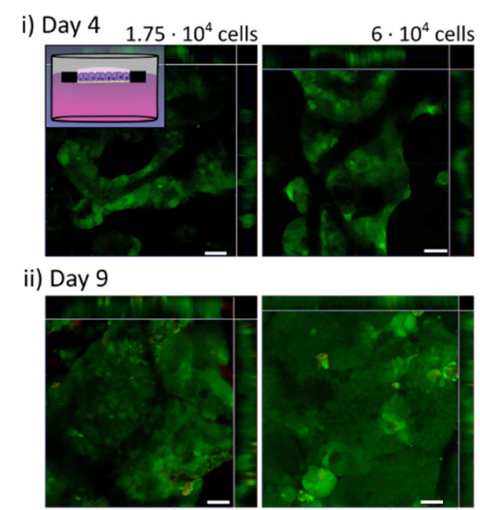

iii) Day 12

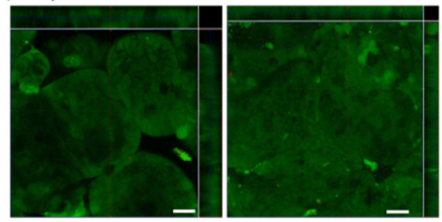

Figure S10. Representative CLSM images of Caco-2 cells cultured in peeled PLL coated paper chips for $4 \mathrm{~d}$ (i), $9 \mathrm{~d}$ (ii) and $12 \mathrm{~d}$ (iii) using different cell seeding densities. The side-views of 3D images are shown on top and right of the CLSM images (green: calcein-AM, red: ethidium homodimer-1). Scale bars are $25 \mu \mathrm{m}$. (n=2)

a) Temperature

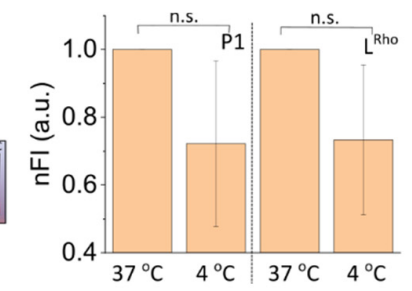

b) Regular paper chip- $\mathrm{HV}_{0.4}^{\mathrm{Rho}}$

i) $9 \mathrm{~d}$

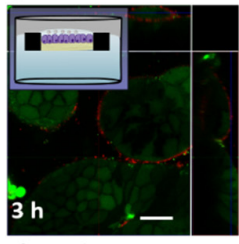

ii) $17 \mathrm{~d}$
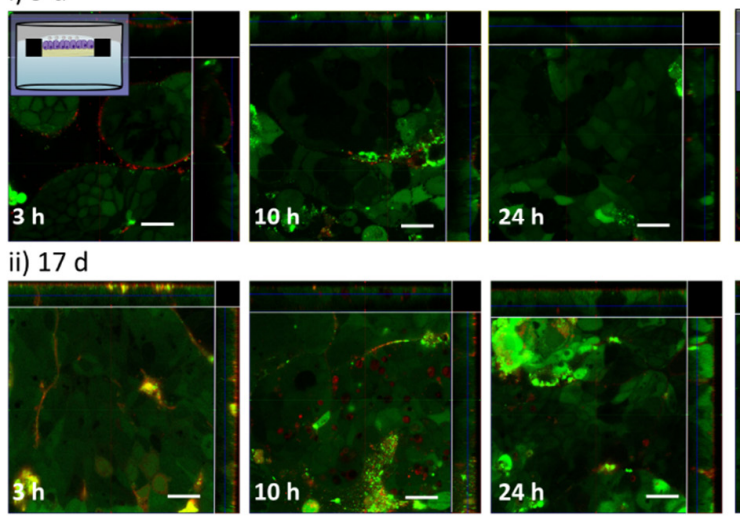

c) Peeled paper chip - $\mathrm{HV}_{0.4}^{\text {Rho }}$

i) $9 \mathrm{~d}$

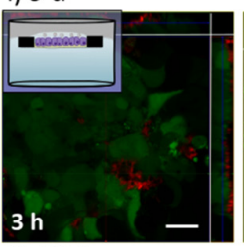

ii) $17 \mathrm{~d}$

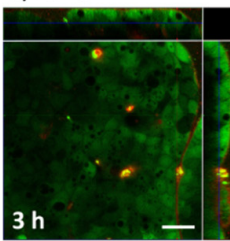

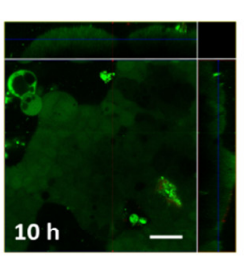
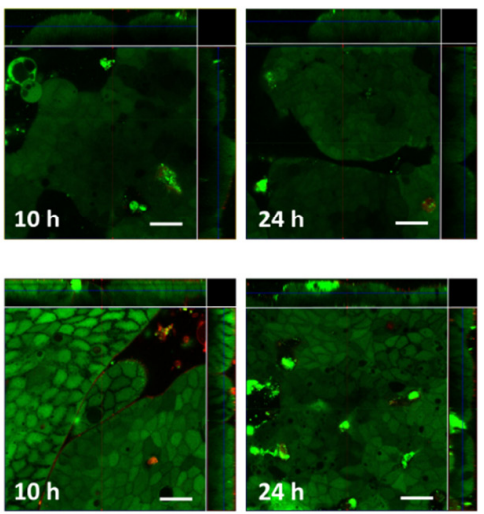
$488 / 595 \mathrm{~nm}$ ) below the floating paper chips containing Caco-2 cells matured for $9 \mathrm{~d}$ and $17 \mathrm{~d}$ and incubated with $\mathrm{HV}_{0.4}^{\text {mix }}$ at either $37^{\circ} \mathrm{C}$ or $4{ }^{\circ} \mathrm{C}$. The data are expressed as mean $\pm \mathrm{SD}(\mathrm{n}=3)$ Representative CLSM images of Caco- 2 cells cultured for $9 \mathrm{~d}$ (i) and $17 \mathrm{~d}$ (ii) in regular (b) and peeled paper chips (c) after $3 \mathrm{~h}$ (left), $10 \mathrm{~h}$ (middle) and $24 \mathrm{~h}$ (right) incubation with $\mathrm{HV}_{0.4}^{\text {Rho }}$. The side-views of 3D images are shown on top and right of the CLSM image. (Red: $L^{\text {Rho }}$, green: calcein-AM). Scale bars $20 \mu m$. $(n=3)$ 
a) CaCo-2 cells

i) Normal paper chip

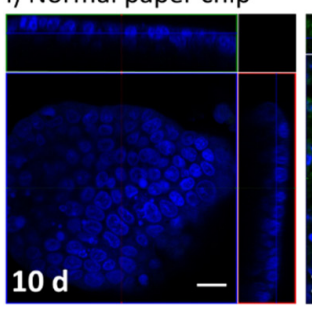

ii) Peeled paper chip

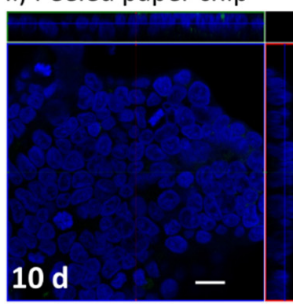

Figure S12. Representative CLSM images of Caco-2 cells (a) and HT29-MTX-E12 cells (b) culture in regular paper chips (i) and in peeled paper chips (ii) for $10 \mathrm{~d}$ and $19 \mathrm{~d}$ (blue: Hoechst 33342 stain of the nuclei, green: mucin staining). Scale bars $20 \mu \mathrm{m} .(\mathrm{n}=3)$

Cocultures of CaCo-2 cells and HT29-MTX-E12 cells Peeled paper chip
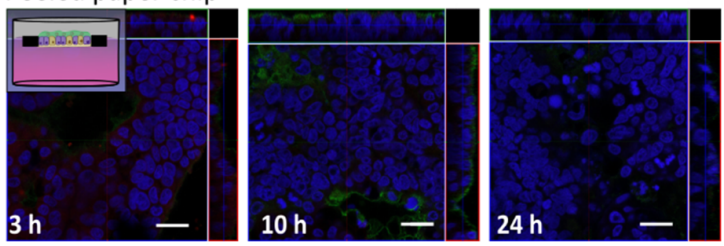

Figure S13. Representative CLSM images of cocultures of Caco-2 and HT29-MTX-E12 cells in peeled paper chips when incubated with $\mathrm{HV}_{0.4}^{\text {Rho }} 3 \mathrm{~h}, 10 \mathrm{~h}$ and $24 \mathrm{~h}$. The side-views of 3D images are shown on top and right of the CLSM image. (Red: $L^{\text {Rho }}$, blue: Hoechst 33342 stain of the nuclei, green: mucin stain). Scale bars $20 \mu \mathrm{m}$. $(\mathrm{n}=3)$

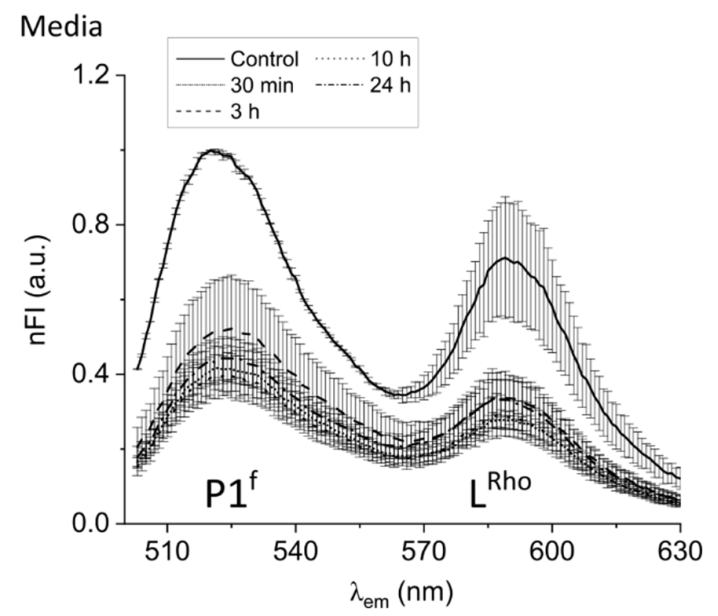

Figure S14. Fluorescent emission spectra $\left(\lambda_{\mathrm{ex}} / \lambda_{\mathrm{em}}=488 / 503-650 \mathrm{~nm}\right)$ of the phenol red free media in the wells when $\mathrm{HV}_{0.4}^{\text {mix }}$ were added to $10 \mathrm{~d}$ matured cocultures in paper chips and let to incubate for $30 \mathrm{~min}, 3 \mathrm{~h}, 10 \mathrm{~h}$ and $24 \mathrm{~h}$. The data are expressed as mean \pm SD $(\mathrm{n}=3)$. 